\title{
Numerical modelling of sluice gates with different baffle types under submerged flow conditions
}

\author{
M. Cihan Aydın a,*, Ali Emre Ulu b \\ a Bitlis Eren University, Department of Civil Engineering, TR-13000, Bitlis Turkey \\ b Bitlis Eren University, Department of Civil Engineering, TR-13000, Bitlis Turkey
}

\section{A R T I C L E IN F O}

Article history:

Received 02 May 2017

Received in revised form 08 June 2017

Accepted 12 June 2017

\section{Keywords:}

CFD

Sluice Gate

Submerged flow

Hydraulic Jump

\begin{abstract}
A B S T RAC T
Computational Fluid Dynamics (CFDs) analyze software package programs recently gained a high importance in hydraulic engineering. The present study investigates how different sills will affect in terms of flow dynamics. In the study, velocity contours and velocity magnitudes for each sill shapes are investigated. The velocity magnitudes are compared by taking 4 cross-sections from the downstream region. Results showed that sills located at downstream of the channel decrease the velocity magnitude at per selected location. Thereby it was concluded that the sill usages could protect the channel bottom from the cavitational and scouring damages due to high flow velocities. In this respect the study will help to the hydraulic designs in this scope.
\end{abstract}

\section{Introduction}

Hydraulic jump is the transition of a flow regime from supercritical to subcritical and it can be observed from hydraulic structures such as spillways and sluice gates. When there is a flow depth difference among the upstream and downstream of a canal separated by a sluice gate, the gate outlet sinks and jump is called submerged (Habibzadeh et al. 2011). Purpose of the use of baffle blocks and sills located in the stilling basins is to improve the energy dissipation and reduce the hydraulic jump length (Peterka, 1984). Depending on the flow characteristics, hydraulic jumps and submerged flows may be seen in the stilling basin if the water depth is high. Hydraulic jump that is generated by baffles and sills creates a high level of turbulence that entraps the air in significant quantities and this causes the velocity measurements difficult in these flow conditions (Hager, 1992). Also, Hager (1992) indicated that the formed hydraulic jumps using baffles and sills generate high levels of turbulence and add significant amounts of air into these flows, so the velocity measurements become difficult (Hager, 1992). Computational Fluid Dynamic (CFD) software programs become common among the various researchers recently. CFD provides more sensitive and detailed data compared to the experimental studies. When all the necessary input data entered to the CFD analyze software, results to be obtained more likely become close with the experimental studies. It has been observed from the literature that many research articles also perform a CFD analyze along with experiments. Some research articles in the literature related to topic is given below.

Gumus et al. (2016) investigated velocity field and surface profiles of a submerged hydraulic jump of a tailwater in an open channel flow. The article compared experimental results to numerical results under same conditions. For the CFD model, different variations of the k- $\varepsilon$ turbulence models which are standard, renormalized, realizable; $\mathrm{k}-\omega$ shear stress transport model; and Reynolds' stress turbulence models are used. The compared results are showed that Reynolds stress model gives the best values among the given turbulence models (Gumus et al., 2016). Gumus et al. (2013), in another study previously, also analyzed submerged hydraulic jump under the sluice gate experimentally and numerically. Habibzadeh et al. (2014) experimentally studied on a submerged hydraulic jump with baffle blocks inserted to the flow regimes of deflected surface jet (DSJ) and reattaching wall 
jet (RWJ). Flows with different velocities, Froude numbers and different size of baffle blocks have been taken into consideration (Habibzadeh et al., 2014). Esmailzadeh et al. (2014) are observed the dynamics of noncritical water flow near the side wall of a rectangular sharp-crested sluice gate. The flow rates of the experimental study were obtained using an acoustic Doppler velocity meter (ADV) (Esmailzadeh et al. 2014). The article by Alminagorta and Merkley (2009) investigates the value of a coefficient $\left(\mathrm{C}_{0}\right)$ that is used to define the threshold between the two regimes, and also the hydraulic transition between the orifice and nonorifice flow regimes in a rectangular channel sluice gate was analyzed. The results show that there is always an orifice flow when the $C_{0}$ coefficient value is lower than 0.83 , and there is always a nonorifice flow when the coefficient is greater than 1.00 (Alminagorta and Merkley, 2009).

In this study, using different types of sills under sluice gates are investigated in two-dimensional domain. The domain used in this study and sill types was carefully chosen from the recent studies in literature. The experimental domain used by Gumus et al. (2016) has taken into consideration for the geometry of channel. A common phenomenon which is submerged flow conditions studied. Yildiz et al. (2015) presents the comparison of the experimental and numerical studies for the flow under the sluice gate. They find out the distance to reach the uniform flow after the hydraulic jump and the study show that the consistency between the experimental study and the numerical model of FLOW-3D.

\section{Method}

As the used method, a common Computational Fluid Dynamic (CFD) software which is FLOW-3D was used. FLOW-3D is a software program that is currently used in many engineering fields that can optimize highly accurate fluid flow simulations such as fluid-solid interactions (i.e. Kumcu, 2017).

FLOW-3D is able to analyze various equations of the turbulence models. For this analyze, the Navier-Stokes equations are used to describe three-dimensional fluid dynamics. Available turbulence options of the software provide is one-equation turbulent energy model, two-equation (k-e) model, Renormalized group (RNG) model and twoequation $(\mathrm{k}-\mathrm{w})$ model. FLOW-3D solves the mass continuity and the Navier-Stokes equations as the momentum equation for each element to estimate properties of fluid motions. These equations can be shown as follows respectively for Cartesian coordinate system (FLOW-3D, 2016).

$V_{F} \frac{\partial p}{\partial x}+\frac{\partial}{\partial x}\left(\rho u A_{x}\right)+\frac{\partial}{\partial y}\left(\rho v A_{y}\right)+\frac{\partial}{\partial x}\left(\rho w A_{z}\right)=R_{D}+R_{S}$

where, $V_{F}$ is volume fraction, $\rho$ is the density of fluid; $R_{D}$ is a turbulent diffusion term; $R s$ is a mass source; $A_{x}, A_{y}$, and $A_{z}$ are the fractional areas in the $x, y$ and $z ; u, v$ and $w$ are velocity components.

In order to describe three-dimensional fluid dynamics, the chosen Navier-Stokes equations are given in Eq.(2):

$$
\begin{aligned}
& \frac{\partial u}{\partial t}+\frac{1}{V_{F}}\left[u A_{x} \frac{\partial u}{\partial x}+v A_{y} \frac{\partial u}{\partial y}+w A_{z} \frac{\partial u}{\partial z}\right]=-\frac{1}{\rho} \frac{\partial p}{\partial x}+G_{x}+f_{x}-\frac{R_{S}}{\rho V_{F}}\left(u-u_{w}-\delta u_{s}\right) \\
& \frac{\partial v}{\partial t}+\frac{1}{V_{F}}\left[u A_{x} \frac{\partial v}{\partial x}+v A_{y} \frac{\partial v}{\partial y}+w A_{z} \frac{\partial v}{\partial z}\right]=-\frac{1}{\rho} \frac{\partial p}{\partial y}+G_{y}+f_{y}-\frac{R_{S}}{\rho V_{F}}\left(v-v_{w}-\delta v_{s}\right) \\
& \frac{\partial w}{\partial t}+\frac{1}{V_{F}}\left[u A_{x} \frac{\partial w}{\partial x}+v A_{y} \frac{\partial w}{\partial y}+w A_{z} \frac{\partial w}{\partial z}\right]=-\frac{1}{\rho} \frac{\partial p}{\partial z}+G_{z}+f_{z}-\frac{R_{S}}{\rho V_{F}}\left(w-w_{w}-\delta w_{S}\right)
\end{aligned}
$$

where; $G_{x}, G_{y}, G_{z}$ are body acceleration components, $f_{x}, f_{y}, f_{z}$ are viscous accelerations components, $u_{w}, v_{w}, w_{w}$ are the components of velocity source; $u_{s}, v_{s}, w_{s}$ are the velocity components at the surface. In this study, incompressible onefluid turbulent model were used to simulate of the all cases.

\subsection{Model}

For the 2D numerical model, sluice gate, and selected three different sill types with dimensions are shown in Fig. 1 for different locations in the domain. Fig. 2 also shows the shapes of the chosen geometries for the sills. The 'a' value shown in the figure 1 is taken as $0.04 \mathrm{~m}$ as it was in Gumus et al. (2016). The value of ' $b$ ' is determined according to the length of ' $a$ '. For all the cases ' $b$ ' value was taken as $b=2 a$. Distance between sills (c) was accepted as 1.5a. First sill height was selected as a/8, second $\mathrm{a} / 4$ and the third one $\mathrm{a} / 2$. First analyze was run without sill to observe and compare the results. Semi-circular sills with different radius and different distance from the gate were also analyzed. Radius of circle 1 and circle 2 were taken 0.02 and 0.04 , respectively. The sill heights are set to a/8, a/4 and a/ 2 respectively as shown in the Fig. 1 .

The all alternatives of sill were performed for two flow conditions case 1 and case 2 which represents two different upstream and downstream free surface levels, as also seen in Fig. 2.

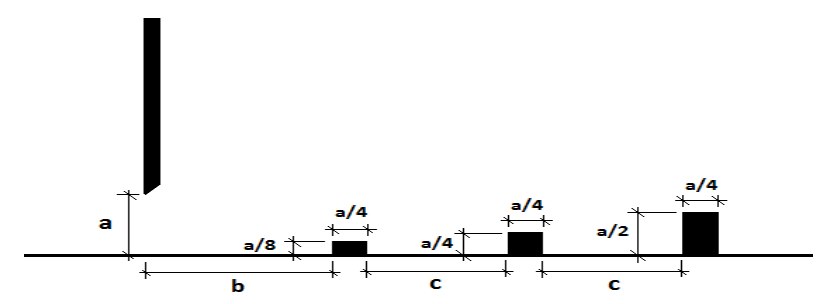

Figure 1. Dimensions of the model. 


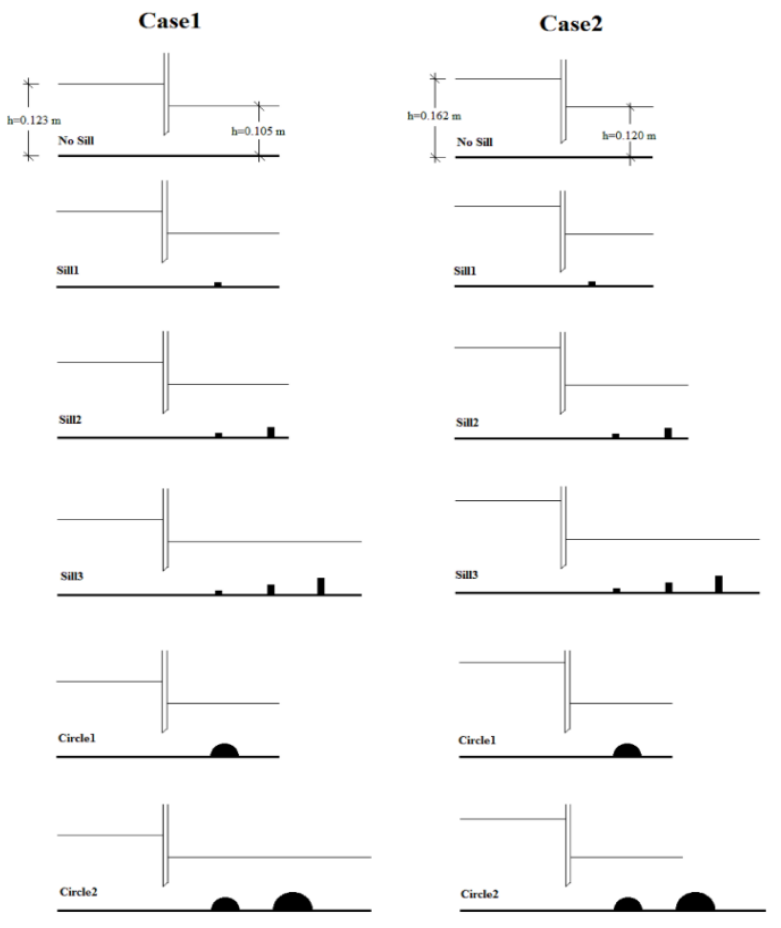

Figure 2. Flow conditions and sill shapes

\subsection{Numerical model}

Fig. 3 shows the mesh structures and boundary conditions. The non-conforming (cells of size $6 \mathrm{~mm}$ ) and conforming meshes (cells of size $3 \mathrm{~mm}$ ) were applied to achieve the mesh sensitivity to numerical solution in terms of solution verifications as shown in Figure 3(a) and (b). Combining the conforming and non-conforming mesh, the solution domain was obtained with structured mesh conforming to near to solid surface, as can be seen in Figure 3(c).

Maximum adjacent cell size ratio was calculated as 1.0 for the both non-conform and conform mesh, which corresponds to very high quality cells used. Figure 3(c) also demonstrates the boundary conditions of the numerical model. The inlet and outlet boundaries were described as pressure inlet and outlet adjusting the pressures and the desired water levels. The top of the model was considered as symmetry boundary to minimize the virtual boundary effects.

The simulation takes approximately 5 minutes for each analyze using two real core xenon processor and $8 \mathrm{~GB}$ ram. One phase renormalized group ( $R N G$ ) turbulence model was used in the numerical solution. The simulation time of the solution convergences is approximately 20 second. Numerical model with $20 \mathrm{~cm}$ height of sluice gate and different height rectangular columns and semi-circular types of sills were used for the all analyzes.
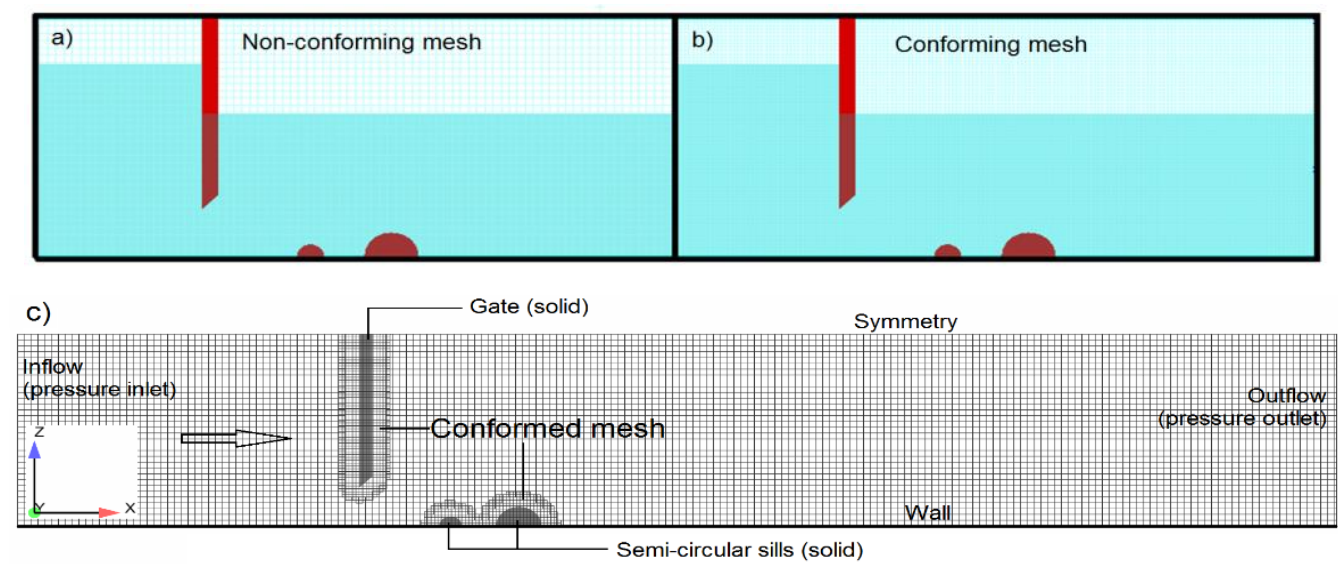

Figure 3. Mesh structures of the solution domain a)Non-conforming mesh, b)Conforming mesh, c)Conformed mesh and boundary conditions

\section{Results and Discussions}

In the present study, the effect on the sluice flow of different sills and baffles located at the downstream of a sluice gate was investigated in terms of velocity distributions and hydraulic jump at the submerged flow condition. Six different sill conditions were tested for both flow conditions named case 1 and case 2 . Thus, totally twelve different numerical models were carried out to observe the sill effects on the flow in an open channel. Table 1 shows the discharges from numerical analysis for the all flow and sill conditions. Although the discharges do not change too much for different sills, the discharge is approximately $0.020 \mathrm{~m}^{3} / \mathrm{s}$ for case 1 and 0.031 $\mathrm{m}^{3} / \mathrm{s}$ for case 2 . The velocity contours obtained from the numerical analysis are shown in figures 4 and 5. Comparing the results obtained in both cases examined, it was observed that the flow rates of sill applications decreased for the same points. According to this situation, it is observed that the sills placed open channel with the sluice gate reduce the average flow rate in the downstream region. As it can be seen from the figures, it appears that the maximum hydraulic jump has occurred when a single sill is used. 
In order to calibrate and verify the numerical results, the obtained velocity profiles from the CFD analysis were compared with the experimental results presented by Gumus et al. (2016) for same flow conditions corresponds to case 1 and case 2 all for $\mathrm{X}=0.75 \mathrm{~m}$ as shown in the Fig. 4. The experimental observations (with Fluent CFD results) presented by Gumus et al. (2016) and the numerical results in this study were illustrated in Fig. 4(a) and (b) for Case 1, and Fig. 4(c) and (d) for Case 2 respectively. These comparative results shows that the numerical results obtained from the CFD analysis are considerably consistent with the experimental results in the literature. These results adequately approve the verifications of the numerical results in this study. As can be seen in the velocity profiles Fig. 4, while the velocities upper the gate opening is close to zero, they are in maximum values against to gate opening for both the results.

Table 1. Discharges for case 1 and case 2.

\begin{tabular}{lcccccc}
\hline $\begin{array}{l}\text { Discharges } \\
\text { (at 20s })\end{array}$ & $\begin{array}{c}\text { No Sill } \\
\left(\mathrm{m}^{3} / \mathrm{s} / \mathrm{m}\right)\end{array}$ & $\begin{array}{c}\text { Sill1 } \\
\left(\mathrm{m}^{3} / \mathrm{s} / \mathrm{m}\right)\end{array}$ & $\begin{array}{c}\text { Sill2 } \\
\left(\mathrm{m}^{3} / \mathrm{s} / \mathrm{m}\right)\end{array}$ & $\begin{array}{c}\text { Sill3 } \\
\left(\mathrm{m}^{3} / \mathrm{s} / \mathrm{m}\right)\end{array}$ & $\begin{array}{c}\text { Circle1 } \\
\left(\mathrm{m}^{3} / \mathrm{s} / \mathrm{m}\right)\end{array}$ & $\begin{array}{c}\text { Circle2 } \\
\left(\mathrm{m}^{3} / \mathrm{s} / \mathrm{m}\right)\end{array}$ \\
\hline Case 1 & 0.0208 & 0.0204 & 0.0203 & 0.0204 & 0.0205 & 0.0205 \\
Case 2 & 0.0312 & 0.0306 & 0.0305 & 0.0305 & 0.0305 & 0.0306 \\
\hline
\end{tabular}
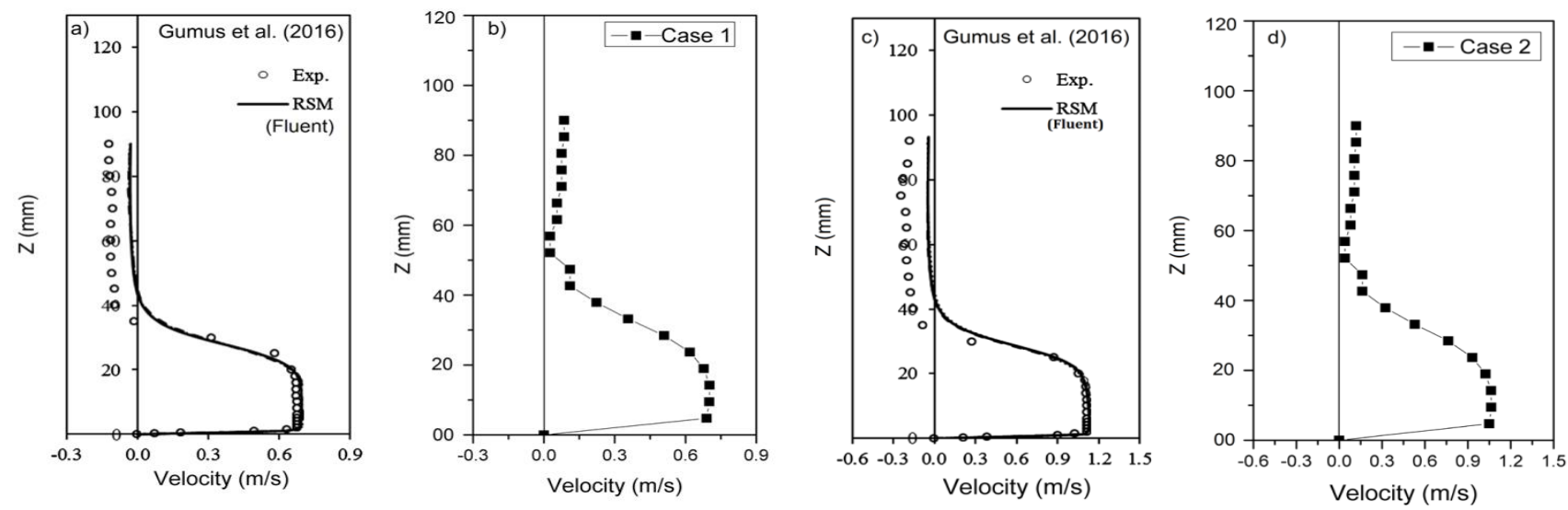

Figure 4. Comparison of CFD results with Experimental observations by Gumus et al. (2016)

The velocity contours on the longitudinal sections for six different sills conditions were presented for Case 1and Case 2 flow conditions respectively in Fig. 5. For rectangular sills, the effects of Sill 2 and Sill 3 conditions are similar to the Sill 1. Sill 1 (only one rectangular sill) can drops the velocities especially at the bottom downstream of the sill. When considering semicircular sills, it is seen that the Circular 2 is more useful than Circular 1 to decrease the velocities at the bottom and maximum velocity length. Therefore apart from rectangular sills, the use of two semi-circular sill (Circular 2) was preferred than one semi-circular sill condition. These discussions are valid at the both flow conditions (Case 1 and Case 2) but for different range of velocities. The maximum velocity length without the sills was also decreased by using sills as seen for the both cases in Fig. 5. The hydraulic jump developed in submerged flow at the downstream of the gate for the all conditions. For no sill, the hydraulic jump length is longer than the other sill conditions but it is not clear. Otherwise, although the hydraulic jump lengths are smaller than that of no-sill condition, they are clearer for the sill conditions except for Circular 1 condition. The shortest hydraulic jump length in the submerged flow developed for Sill 1 and Sill 2 conditions. The minimum velocity point on the downstream surface were considered to determine the hydraulic jump length (L). The all sections shows that the sills reduced the velocity on the bottom and hydraulic jump length especially for Sill 1 condition. Therefore, it can be noted that the sills will protect the channel bottom from some damage e.g. cavitation and scours which is important for design of hydraulic structures. The sill can also help to short the energy dissipation pools as reducing the hydraulic jump length. 

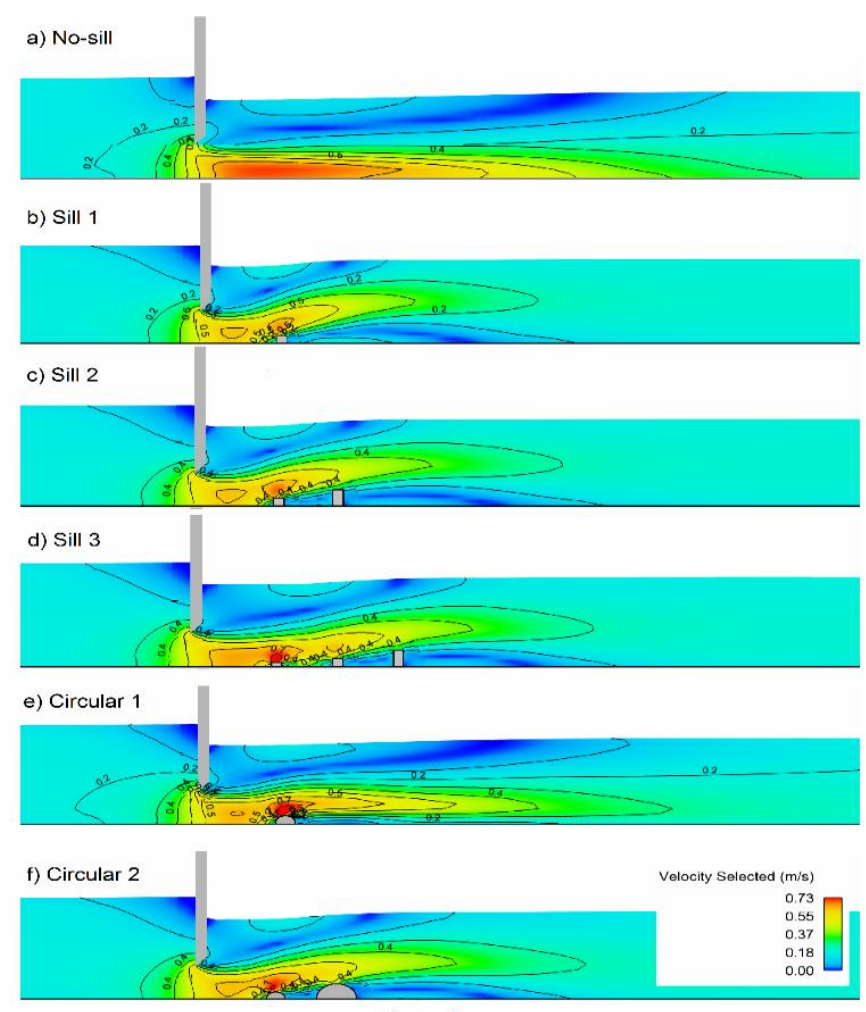

Case 1

Figure 5. Velocity profiles for different sill and flow conditions

The velocity profiles along the flow height for different locations were plotted for the all sill conditions in the graphs in Figures 6 for Case 1 and Figure 7 for Case 2. The maximum velocities near to the channel bottom found at the no-sill and the circle 1 conditions while there are no differences at the $\mathrm{x}=0.75 \mathrm{~m}$ corresponding just downstream of the sluice gate. Sill 1, Sill 2 and Circle 2 conditions presents similar profiles for the both flow cases. The most suitable velocity profile were achieved for Sill 1 and Sill 2, but the Sill 1 conditions can be
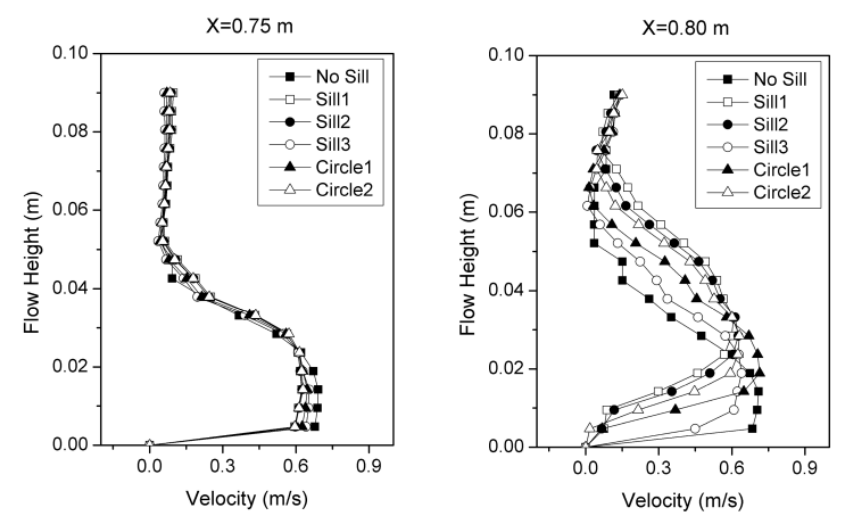

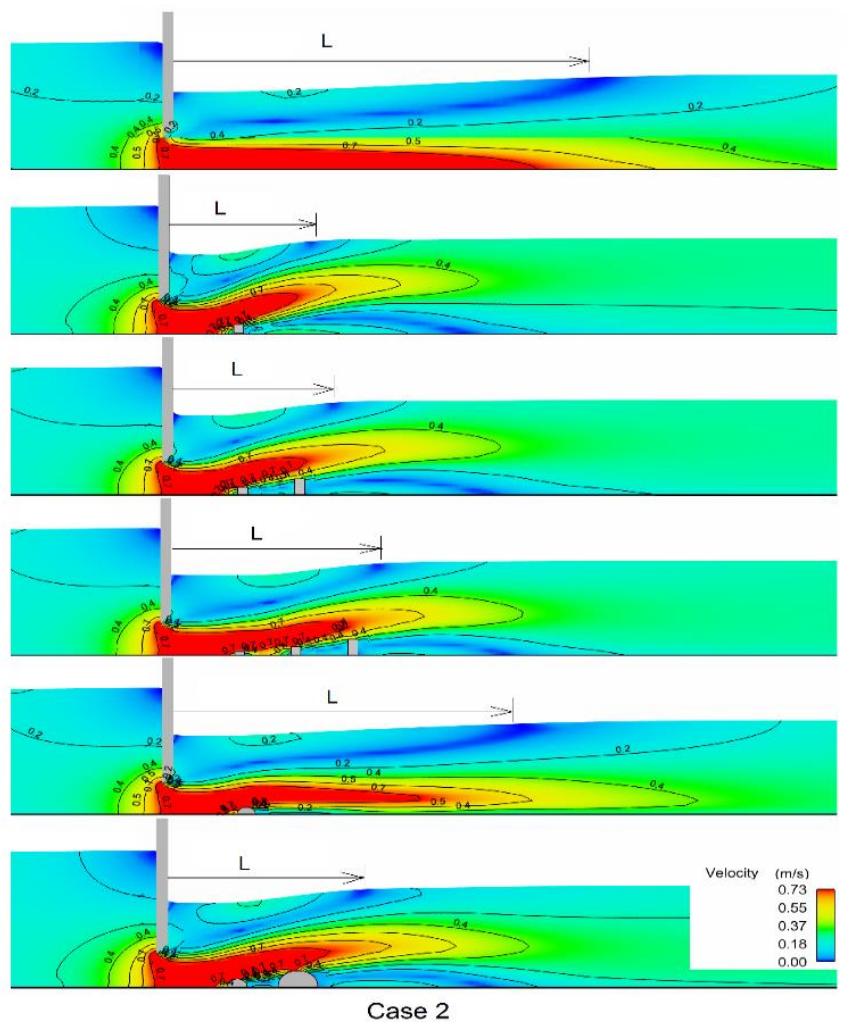

preferred in terms of cost. At the farthest section $(X=0.94)$, velocity profile for Sill 1 ensures the most uniform distribution. The similar results were determined for Case 2 flow condition as shown in Figure 6. The all sills considerably decrease the velocities especially at the bottom downstream of the sills. Therefore, as also mentioned above, the sill elements (the most efficient is Sill 1 condition in this study) can protect the downstream channel bottom from the effects of high velocity of flow such as scour and cavitation, by dissipating the energy of flow.
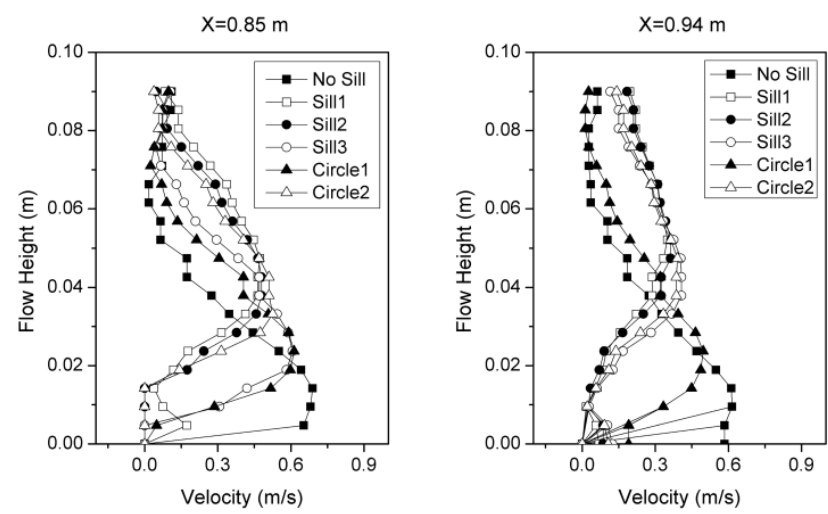

Figure 6. Velocity magnitudes for case 1 . ( $X=0.74 \mathrm{~m}, \mathrm{X}=0.82 \mathrm{~m}, \mathrm{X}=0.88 \mathrm{~m}, \mathrm{X}=0.92$ ) 

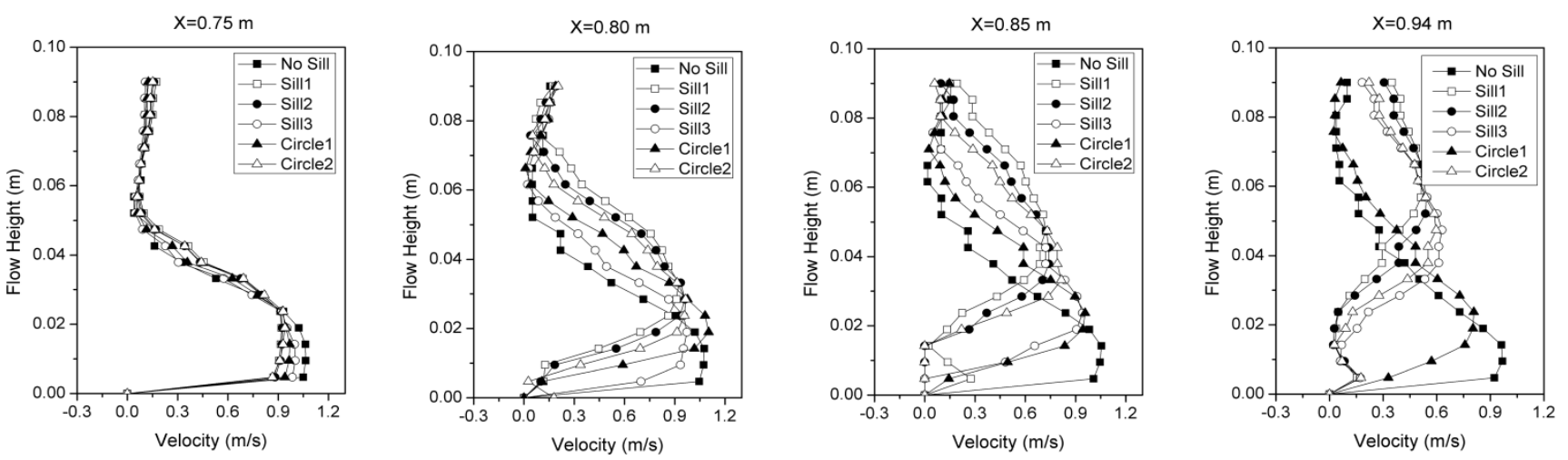

Figure 7. Velocity magnitudes for case 2 . $(X=0.74 \mathrm{~m}, \mathrm{X}=0.82 \mathrm{~m}, \mathrm{X}=0.88 \mathrm{~m}, \mathrm{X}=0.92 \mathrm{~m})$

\section{Conclusion}

Using numerical analysis program FLOW-3D, hydraulic jumps and velocity profiles in the downstream region were investigated using different sills in a submerged sluice gate with free surface. First, the CFD analysis results were verified by comparing some experimental data (velocity profiles) for same flow conditions. Then, different sill and flow conditions, the flow downstream of the sluice gate were investigated by using CFD simulations. The results show that the all sill conditions considerably decrease the velocities especially near to channel bottom. However, instead of the multi-sill using, only one sill using (Sill 1 condition) provided more efficient solution than the other in terms of cost did. Moreover, the Sill 1 and Sill conditions ensure shorter hydraulic jump length. Consequently, it can be stated that the use of the sill can be protect the channel bottom from undesirable damages due to high flow velocities, e.g. scour and cavitation damages. It can be seen from this study that the CFD simulation technic is a useful tools to analysis of the hydraulic structures.

\section{References}

Alminagorta, O., and Merkley, G. P., 2009. Transitional flow between orifice and nonorifice regimes at a rectangular sluice gate. Journal of Irrigation and Drainage Engineering, 135(3), 382-387.

Esmailzadeh, M., Heidarpour, M., and Eslamian, S. S., 2014. Flow characteristics of a sharp-crested side sluice gate. Journal of Irrigation and Drainage Engineering, 141(7), 06014007.
FLOW-3D, User Manual, Theory Guide, 2016.

Gumus, V., Akoz, M. S., and Kirkgoz, M. S., 2013. Kapak Mansabında Batmış Hidrolik SıçramanınDeneysel ve Sayısal Modellenmesi. IMO Teknik Dergi, 399, 6379-6397.

Gumus, V., Simsek, O., Soydan, N. G., Akoz, M. S., and Kirkgoz, M. S., 2015. Numerical modeling of submerged hydraulic jump from a sluice gate. Journal of Irrigation and Drainage Engineering, 142(1), 04015037.

Habibzadeh, A., Loewen, M. R., and Rajaratnam, N., 2014. Mean flow in a submerged hydraulic jump with baffle blocks. Journal of Engineering Mechanics, 140(5), 04014020.

Habibzadeh, A., Wu, S., Ade, F., Rajaratnam, N., and Loewen, M. R., 2011. Exploratory study of submerged hydraulic jumps with blocks. J. Hydraul. Eng., 10.1061/(ASCE)HY.1943-7900.0000347, 706-710.

Hager, W. H., 1992. Energy dissipators and hydraulic jump, Kluwer, London.

Kumcu, S. Y., 2017. Investigation of flow over spillway modeling and comparison between experimental data and CFD analysis. KSCE, 21 (3), 994-1003.

Peterka, A. J., 1984. Hydraulic design of stilling basins and energy dissipators, 8th Ed. Engineering Monograph No. 25, U.S. Bureau of Reclamation, Denver.

Yildiz, A., Kumcu, S. Y., and Mart, A. I., 2015. Observation of hydraulic jump phenomena by using CFD and comparison of numerical and experimental study. Proceeding of MAC-ETL, Prague. 